\title{
La resistencia y la sobrevivencia de la justicia indígena en Colombia*
}

Recibido: 25 de agosto de 2015 • Aceptado: 25 de noviembre de 2015

Resistance and the Survival of the Indigenous Justice in Colombia

La résistance et la survie de la justice autochtone en Colombie

A resistência e a sobrevivencia da justiça indígena na Colômbia

Natalia Ruiz Morato ${ }^{a}$

* Artículo producto de la investigación doctoral cursada en el programa de doctorado en Derecho de la Universidad Nacional de Colombia.

a Universidad Militar Nueva Granada, Bogotá, Colombia. PhD en Derecho, Magíster en Estudios Internacionales con énfasis en Desarrollo Internacional y abogada. Investigadora jurídica, docente universitaria y consultora en temas de desarrollo internacional para instituciones privadas y públicas. Comentarios a: ruiznatalia@ gmail.com 
Resumen. Se realizó una investigación histórica y socio-jurídica sobre el funcionamiento de la Jurisdicción Especial Indígena para ubicar las tensiones y dificultades entre la jurisdicción ordinaria. El estudio determinó que existen relaciones no amigables entre justicia indígena y la justicia ordinaria y una negación de la aplicación de la Ley de Origen como forma válida de solución de conflictos de los pueblos indígenas en Colombia. Como principal resultado se evidenció la imposibilidad del sistema jurídico colombiano de armonizar el pluralismo jurídico creado en la Constitución Nacional de Colombia, por lo cual la Jurisdicción Especial Indígena es forma de supervivencia y reivindicación de los grupos indígenas en Colombia. Como alternativa de salida se propone la incorporación de esquemas democráticos deliberativos para sociedades multiétnicas.

Palabras claves: Jurisdicción especial indígena, pluralismo legal, reivindicaciones indígenas, estudio socio jurídico.

Abstract. This paper presents historical and sociolegal research on the operation of the Special Indigenous Jurisdiction, which was conducted with the aim of locating the tensions and difficulties within ordinary jurisdiction. This study identified enimical relations between jurisdictions, and a negation of the law as source application valid form of conflict resolution of indigenous peoples in Colombia. The main result thus evidenced is that of the inability of the Colombian legal system to harmonize the legal pluralism established in the Colombian constitution, and thus the Special Indigenous Jurisdiction is a means of survival and vindication of indigenous groups in Colombia. An alternative solution is proposed in shape of an incorporation of deliberative democratic schemes for multi-ethnic societies.

Keywords: Special Indigenous Jurisdiction, legal pluralism, indigenous vindications, sociolegal research.

Résumé: Résumé. Cet article présente une recherche historique et sociojuridique sur le fonctionnement de la juridiction indigène spéciale, qui a permi localiser des tensions et des difficultés parmi les tribunaux ordinaires. Létude a révélé qu'il n'y a pas de relations amicales entre la justice autochtone et la justice ordinaire, et qu'il y existe une tendence de nier l'application de la loi d'origine comme une forme valide de la résolution des conflits des peuples autochtones en Colombie. Le principal résultat est celui de l'impossibilité du système juridique colombien à harmoniser le pluralisme juridique établie dans la Constitution colombienne, ainsi que la juridiction spéciale autochtone est un moyen de survie et de revendication des groupes autochtones en Colombie. On propose una solution alternative, soit l'inclusion de mécanismes démocratiques de délibération pour les sociétés multi-ethniques.

Mots-clés: Juridiction spéciale autochtone, pluralisme juridique, justifications autochtones, recherche sociojuridique.

Resumo. Foi efectuada uma revisão histórica e socio-jurídica sobre o funcionamento da Jurisdição Especial Indígena para determinar as tensões e desafios entre a jurisdição comum. $\mathrm{O}$ estudo apurou que existiam relaçôes não amigáveis entre justiça indígena e a justiça comum e uma negação da aplicação da Lei de Origem como forma válida de resolução de conflitos dos povos indígenas na Colômbia. Como o principal resultado se evidenciou a impossibilidade do sistema jurídico colombiano de harmonizar o pluralismo jurídico criado pela Constituição Nacional de Colômbia, por causa disso a Jurisdição Especial Indígena é uma forma de sobrevivência e de reivindicação dos grupos indígenas na Colômbia. como forma alternativa de escoamento propor-se a incorporação de esquemas democráticos deliberativos para sociedades multi-étnicas.

Palavras-chave: Jurisdição Especial Indígena, pluralismo legal, reivindicações indígenas, estudo socio-jurídico. 


\section{Introducción}

La investigación histórica y socio-jurídica de la Jurisdicción Indígena, tiene como principal objetivo realizar una evaluación de su evolución y funcionamiento desde el año 1991, donde se quiere ver las tensiones y dificultades que se presentan en esta jurisdicción para demostrar las incoherencias sistémicas del ordenamiento jurídico Colombiano donde se reproducen las desigualdades entre grupos étnicos y la sociedad mayoritaria.

La metodología propia de un estudio socio-jurídico integra las variables que caracterizan Jurisdicción Indígena y que se correlacionan con efectos causales entre ellas que determinan cómo se ha venido desarrollando la figura en Colombia. Dada la complejidad del estudio se exploró el fenómeno desde diferentes métodos: 1. Métodos de análisis históricos y discursivo de fuentes primarias y secundarias especializadas nacionales e internacionales para entender la evolución de la regulación y de las políticas públicas que han incidido en la operación de la Justicia Indígena. 2. Aplicación de entrevistas semi-estructuradas con los actores principales ubicados en la ciudad de Bogotá (instituciones públicas y principales Organizaciones Nacionales Indígenas) y requerimiento de información oficial de las Entidades Públicas para la ubicación de las características, diagnósticos, dificultades de la aplicación de la jurisdicción indígena.

\section{Conceptualización de la justicia indígena en Colombia}

Técnicamente se le denomina Jurisdicción Especial Indígena en Colombia, está establecida como parte fundamental en el Estado Social de Derecho pluriétnico, pluricultural, democrático y participativo consagrado en la Constitución Política de 1991. Esos valores y fines del Estado han desarrollado la fundamentación de la cultura como parte de la nación que se evidencia en complementariedad con los diferentes derechos, obligaciones y garantías: protección de la riqueza cultural de la nación y patrimonio arqueológico, el derecho a la autodeterminación de los pueblos, protección de las lenguas de grupos étnicos, reconocimiento de la igualdad y dignidad de las culturas. A su vez se ha ampliado la Carta Constitucional por la Declaración de las Naciones Unidas sobre los derechos de los Pueblos Indígenas- Convenio 169 de la OIT por medio de la Ley 21 de 1991.

Los anteriores preceptos constitucionales e internacionales han venido configurando la Jurisdicción Especial Indígena establecida como:

Las autoridades de los pueblos indígenas podrán ejercer funciones jurisdiccionales dentro de su ámbito territorial, de conformidad con sus propias normas y procedimientos, siempre que no sean contrarios a la Constitución y leyes de la República. La ley establecerá las formas de coordinación de esta jurisdicción especial con el sistema judicial nacional.

Artículo 246 de la Constitución Nacional de Colombia. 
La Jurisdicción Especial Indígena, está ligada con la aplicación del "Ley de Origen”:

Son las raíces originarias y los principios rectores de cada pueblo indígena, establece las maneras de relacionarse consigo mismo, con la comunidad, con la naturaleza y con el universo; con el propósito de mantener el equilibrio y la armonía entre el ser y la naturaleza.

PNUD, 2013, p. 19

La ley de origen determina el desarrollo indígena, su forma de gobierno, la forma de educación, como se debe manejar la salud, y el goce mismo de los derechos colectivos que tienen como pueblo.

\section{Evolución histórica de los derechos de los pueblos indígenas. "Tensiones y conflictos que desbordan los Estados Nacionales en la Globalización. Protección Internacional y las reivindicaciones de los pueblos indígenas"}

La evolución histórica de la figura de Jurisdicción Indígena en Colombia está íntimamente ligada con el establecimiento de los derechos de los pueblos indígenas. Esto ha dependido de varios factores el primero, el derecho indiano, segundo, los tratados internacionales de los Pueblos Indígenas y el Sistema de Naciones Unidas que monitorea su aplicación; tercero, la forma que se decidió constitucionalmente de Jurisdicción Indígena gracias a los movimientos indígenas desde los años setenta, cuarto, las reivindicaciones y poder de movilización de los pueblos indígenas para garantizar sus derechos colectivos y finalmente, los debates dentro de la Jurisdicción de la Corte Interamericana de Derechos Humanos y la jurisdicción constitucional que ha determinado el devenir de la figura y especiales protecciones a los grupos étnicos.

La evolución histórica ha demostrado que a pesar de que en Colombia a partir de la Constitución Nacional en 1991 de un estado pluriétnico donde se garantiza la Jurisdicción Indígena, esto ha tenido tensiones muy profundas que han desbordado la capacidad misma del Estado, al ser un estado con débil capacidad institucional de garantizar los derechos humanos a los pueblos indígenas y que a su vez son víctimas del conflicto armado.

La jurisdicción indígena es la aplicación de la cosmogonía de los pueblos en su vida diaria, concepto que se está reivindicando actualmente por los pueblos indígenas en Colombia e Internacionalmente. Por lo tanto esta figura tiene su origen desde la consolidación de estos pueblos aún antes de la Conquista española. No obstante, la jurisdicción indígena su primera reconfiguración fue a través del Derecho Indiano, tiene como fundamento los principios del Derecho de Gentes desarrollados por teólogos y filósofos iusnaturalistas de los siglos XVI y XVII que determinaron el tratamiento de la población aborigen americana (Sánchez, 1993, p. 25) que partieron de la idea de que la población indígena era potencialmente cristiana para el proyecto colonizador, por lo cual se establecieron derechos y bienes a Resguardos y Cabildos Indígenas bajo un universalismo occidental concebido por la elite espańola.

${ }^{1}$ En los estudios y literatura consultada se encuentra que se usan como sinónimo Derecho indígena, Derecho Propio, o sistema de justicia indígena. En esta caracterización se usa el concepto de Ley de origen que es el concepto que están reivindicando actualmente los pueblos indígenas colombianos. 
Esa tradición de derecho indiano en el Estado Moderno Colombiano, dio como resultado la Ley 89 de 1890 "Por la cual se determina la manera como deben ser gobernados los salvajes que vayan reduciéndose a la vida civilizada", ley que está parcialmente exequible con la Constitución Nacional de Colombia de 1991. Sus desarrollos posteriores en el siglo XX, determinaron que el reconocimiento de los derechos de los pueblos indígenas dependía de su poder de organización por territorios- Cabildos, resguardos y organizaciones indígenas ${ }^{2}$. Por lo que se evidencia el proyecto homogeneizador del Estado Colombiano que todavía se evidencia en las reivindicaciones de la figura de la Jurisdicción Indígena.

En el contexto de la globalización, el sistema de Naciones Unidas y los movimientos internacionales indígenas han afectado los Estados Nacionales como se evidencia en el caso Colombiano que el desarrollo de la figura de la Jurisdicción Indígena en el año de 1991 es gracias a la dinámica internacional de los derechos humanos reconocidos a los pueblos indígenas. Fenómeno también que explica Fraser (1997), de la opinión pública global y contra públicos ${ }^{3}$ que ha incidido en la forma como los Estados Nacionales se comprometan hacer acciones positivas de protección en derechos humanos a los Pueblos Indígenas.

Los derechos de las comunidades étnicas, se ha enfocado en el siglo XX hacia los pueblos indígenas, que ha venido estructurando unidades regionales (Europa, África y América), dinámicas que se han suscitado en el contexto de la ONU y de la OIT y en especial en América Latina en el Sistema Interamericano de Derechos. Como hito se cuenta con el Convenio 107 de la OIT de 1957 y Convenio 169 de 1989 que propuso el marco jurídico para la regulación entre Estados y Pueblos Indígenas, que si bien en el desarrollo histórico de la regulación en el Siglo XX se cuenta con los siguientes instrumentos internacionales: la Declaración que Garantiza la Independencia de los Pueblos Colonizados, de 1960; la Resolución sobre la Soberanía Permanente sobre Recursos Naturales, de 1962; la Declaración de las Naciones Unidas sobre la Eliminación de todas las Formas de Discriminación Racial de, 1963; la Declaración contra la Discriminación de la Mujer, de 1967; la Declaración sobre el Progreso Social y el Desarrollo de 1969; la Declaración sobre la Raza y los Prejuicios Raciales, de 1978 ; la Declaración sobre la Eliminación de todas las Formas de Intolerancia y Discriminación Fundadas en la Religión o las Convicciones, 1981; la Declaración sobre Derecho al Desarrollo y la Declaración sobre los Derechos de las Personas que Pertenecen a las Minorías étnicas, Religiosas y Lingüísticas, de 1992; la Declaración de Viena

2 En oposición de la ley 55 de 1905 se determinó la potestad de los entes territoriales para extinguir los resguardos, lo cual desató el movimiento Quintín Lame en los años setentas, lo cual el programa de lucha de los movimientos indígenas y sus organizaciones: "recuperación y ampliación de las tierras de los resguardos, fortalecimiento de los cabildos, el no pago de terraje, dar a conocer las leyes indígenas y su justa aplicación, defender la lengua, historia y costumbre indígena y formar profesores indígenas" (PNUD, 2013). De la Gran Marcha Campesina de 1972, salieron la Organización Nacional Indígena de Colombia ONIC en 1982 y otros grupos que han logrado estar presentes en la Constituyente sino también se han estado movilizando por en los espacios de participación del Estado y por acciones de tutela a sus derechos.

3 La opinión pública es la esfera pública, en el sentido de Habermas como un foro de las sociedades modernas donde se lleva a cabo la participación política como espacio de interacción discursiva, donde está presente el estado, mercados económicos y asociaciones democráticos - personas privadas para discutir asuntos públicos (Fraser 1997,97). Sin embargo, la esfera pública es un mecanismo de racionalización de dominación política (ibíd., 99). Según Fraser (1997, 114) consiste que en sociedades estratificadas los acuerdos que incluyen la confrontación entre una pluralidad de públicos [subalternos] promueven mejor el ideal de la paridad en la participación que un público único, comprehensivo y abarcante. Esto permite el flujo de contra-discursos y permite formular interpretaciones opuestas de identidades intereses y necesidades, hay una negociación cultural e ideológica. 
sobre Derechos Humanos de 1993, que replantea los estándares individualistas establecidos de la Declaración de 1948, y la Declaración de Durban en el año 2000.

La Declaración de las Naciones Unidas sobre los Derechos de los Pueblos Indígenas de 2007 de la sesión 61 de la Asamblea General de las Naciones Unidas no es un instrumento coercitivo, pero es un desarrollo legal internacional y del compromiso de la comunidad internacional para la eliminación de violaciones de derechos humanos contra 370 millones de indígenas en el mundo, para apoyarlos en su lucha contra la discriminación (UN News Center 2010). Por lo cual, se consagran derechos colectivos e individuales de los pueblos indígenas, el derecho a la tierra, a sus recursos, a su cultura, a su identidad, lengua, empleo, salud, educación, determinar libremente su condición política y su desarrollo económico, a propender por su propia visión económica y social y derecho a la participación efectiva ${ }^{4}$.

Hace parte de la política y derecho internacional los derechos de los pueblos indígenas y de las comunidades locales, el rol del conocimiento tradicional y conocimiento indígena para el manejo de la conservación de la diversidad, esto como respuesta alternativa frente a la crisis ambiental las Naciones Unidas promulgó la Convención de la Diversidad Biológica de 1993. Esta situación bien catalogada por gran parte de la comunidad académica como SoftLaw, esto refuerza los derechos de los indígenas, ya que la regulación sobre el tratamiento del conocimiento tradicional y diversidad biológica imponen limites a la investigación científica para acceder a dichos conocimientos y recursos de las comunidades locales. Como directiva se dispone que dicha comunidad debe participar en las diferentes escalas de la actividad científica y el respeto del valor del conocimiento indígena (Mauro, 2000, p. 1263). Según Mauro (2000, p. 1266) armonizan la Convención de la Diversidad Biológica, con respecto a la protección del conocimiento indígena: La Convención Internacional para Combatir la Desertificación de 1994, la Declaración de Río de 1992, el Fórum Intergubernamental sobre los Bosques de 1996, y las propuestas propias de los indígenas en la Declaración de Kari-Oka de 1992. Es decir, se han reconocido los pueblos indígenas como actores cruciales para la conservación de los ecosistemas más vulnerables al cambio climático.

El Sistema de Naciones Unidas con sus diferentes Declaraciones y sus Agencias, como también la incidencia de Organizaciones Internacionales a que en los estados nacionales de América Latina establecieran nuevas constituciones nacionales que reformaron la idea de un estado unitario. Se consagran estados plurinacionales, multiétnicos y multiculturales donde se acepta la Jurisdicción Indígena. La Constitución Colombiana de 1991, la Constitución de Ecuador de 1998, la Constitución de Venezuela de 1999, la Constitución de Brasil de 1988, el sistema de Autonomías Indígenas de la Costa Atlántica de Nicaragua de 1987 y la Constitución de Paraguay

4 Sin embargo, las negociaciones y ratificación de la Declaración de las Naciones Unidas sobre los Derechos de los Pueblos Indígenas solo sufrió el veto de 4 países- Estados Unidos, Canadá, Nueva Zelanda y Australia- 11 abstenciones y 34 países no estuvieron presentes en las votaciones. Para el análisis los países en contra de dicho instrumento, demuestran argumentativa las posiciones reales que afectan la eficacia de estos, que se reproducen a nivel local. Los principales argumentos son primero, contra el mantenimiento de los sistemas jurídicos tradicionales indígenas, Australia consideró que "debe haber solamente una ley para todos los australianos y no debemos mantener como reliquia prácticas legales que no son aceptables en el mundo moderno (BBC News 2007), otra imposibilidad es la devolución de territorios históricos, es irrealizable en una democracia occidental bajo gobierno constitucional, y como lo expreso el gobierno de Estados Unidos, la declaración no tiene una clara definición del concepto de pueblos indígenas ni de lo que exactamente intenta abarcar (Shunpinking 2010) 
1992 son los casos prominentes en consagración de los derechos indígenas a nivel constitucional, que se pueden catalogar como la acumulación de procesos jurídicos y políticos que se producen en el orden nacional e internacional que complementarios y contradictorios, son resultado de movimientos sociales 5 .

El reconocimiento de los derechos de los pueblos indígenas dentro de un sistema moral y jurídico no ha sido fácil. Sin embargo, Los movimientos indígenas han logrado la imposición diferencia cultural, o la distinción de la identidad cultural esto es un desarrollo emancipatorio de significancia histórica mundial (Turner, 2003, p. 50). Por lo tanto, el movimiento indígena es mejor entendido como una respuesta al proceso de discriminación severa y expropiación. Este proceso reconoce la equidad tiene que estar basada en el reconocimiento y la negociación de la diferencia en vez de la insistencia de la creación de una homogeneidad cultural en una situación donde siempre crece la inequidad económica ${ }^{6}$ (Kenrick, 2004, p. 9) que es lo que se ha hecho es implantar el desarrollo como si fuera una sociedad homogénea en sociedades multiculturales.

En el caso particular, la Jurisdicción Indígena en Colombia implica la adopción del pluralismo jurídico que refiere a la coexistencia de sistemas jurídicos diversos dentro de un mismo campo social, lo cual cuestiona la visión etnocéntrica del derecho occidental, que ha sido construida asignándole el papel de único y legítimo referente de derecho por el positivismo jurídico, concepción ésta que vino a respaldar y consolidar la empresa colonial (Fitzpatrick ,1998).

El pluralismo jurídico no es solamente una característica de sociedades con pasado colonial, sino una propiedad de las sociedades contemporáneas estructuradas por una diversidad de sistemas jurídicos interconectados, como lo señala Santos (1991), para quien el planteamiento central del pluralismo jurídico es ver al derecho como un universo policéntrico de órdenes jurídicos o formas diversas de derecho interconectados y sobrepuestos (interlegalidad), y pueden abordarse según su escala, su proyección y su simbología. Sobre estos mecanismos.

[Los] desarrollos socio-jurídicos revelan, pues, la existencia de tres espacios jurídicos diferentes a los que corresponden tres formas diferentes de derecho: el derecho local, el derecho nacional y el derecho mundial. Es poco satisfactorio distinguir estas formas de derecho con base en el objeto de regulación pues, a veces, regulan o parecen regular el mismo tipo de acción social. En mi entender, lo que distingue a estas formas de derecho es el tamańo de la escala con que regulan la acción social. El derecho local es una legalidad de grande escala; el derecho nacional estatal es una legalidad de mediana escala; el derecho mundial es una legalidad de pequeña escala [...] Los diferentes órdenes jurídicos operan así en escalas diferentes y, con eso, traducen objetos empíricos eventualmente iguales en objetos jurídicos distintos.

Santos (1991, p. 223-224)

5 En América Latina está creciendo la participación de los movimientos indígenas en las democracias para luchar con los desafíos de la consolidación de un régimen, como es el caso de la Confederación de las Nacionalidades Indígenas de Ecuador CONAIE, que llamó a una asamblea constitucional para poder validar los derechos indígenas y reestructurar el Ecuador a Estado Plurinacional (Andolina 2003, 721) que como resultado es la Constitución Nacional de Ecuador de 1998. Los casos de Colombia y su constituyente de 1991 donde participaron indígenas, las negociaciones de paz en Guatemala en 1996 por asociaciones cívicas, y el movimiento en Porto Alegre Brasil en la participación del presupuesto, hacen de los movimientos indígenas latinoamericanos actores principales en el proceso de la insistencia de las diferencias culturales y en las identidades colectivas retan a los estados para plantear una ciudadanía activa y multicultural (Andolina 2003, 724).

6 Para Kenrick, el sistema internacional y los sistemas internos no han ha podido reconocer los valores que ponen en peligro tanto las relaciones de poder sostenidas por las sociedades dominantes y por el aumento de la desigualdad del mercado mundial. 
Sobre el tema del pluralismo jurídico y el uso de este concepto para analizar la situación de los países que forman parte de la sistematización, interesa resaltar las siguientes dos definiciones, debido a que se considera al revisar las constituciones de los mismos, que es posible entrever como América Latina tiene una clara tendencia hacia el pluralismo del primer tipo, tal como lo plantea André Hoekeman (1998): Pluralismo de tipo unitario: es el reconocido por el Estado en la Constitución pero reservándose la facultad, unilateralmente, de determinar la legitimidad y el ámbito de los demás derechos. Otra corriente es el Pluralismo igualitario, que reconoce la validez de normas de los demás sistemas de derecho, su fuente especial es una comunidad que como tal conforma una parte diferenciada pero constitutiva de la sociedad entera y por tanto tiene derecho a que su derecho sea reconocido como parte integral del orden legal nacional por los demás.

Naciones Unidas en el año 2009, publicó “State of the World's Indigenous Peoples”, donde reporta que los pueblos indígenas se ven inmersos en conflictos con la sociedad dominante, relacionados con la pérdida de sus tierras, territorios y recursos o la privación de sus derechos civiles, políticos, culturales, sociales y económicos, lo que encrudece la pobreza y la pérdida del bienestar de su gente. El rápido paso de la globalización ha acelerado dichos conflictos y los pueblos indígenas tienen la necesidad de acceder a mecanismos de resolución de conflictos pacíficamente (Naciones Unidas, 2009, p. 222). Ese mismo año, la Corte Constitucional colombiana reconoce en el Auto 009 de 2009 la vulnerabilidad de los pueblos indígenas en Colombia y su peligro de extinción por lo cual obliga al Estado Colombiano a establecer una política especial de atención.

Según Hettne (1996, p. 22-24), la fuente de los conflictos y las tensiones entre los Estados y las comunidades étnicas e indígenas, como, la desigualdad de las tendencias a largo plazo son producto de la modernización, la urbanización y los cambios demográficos, la competencia por el control de los recursos naturales, los proyectos industriales y de grandes infraestructuras que afectan los sistemas ecológicos locales. Por lo cual, los diferentes efectos que las estrategias de desarrollo tienen en las comunidades son problemas en la distribución de bienes públicos entre los grupos definidos culturalmente.

Desde la década de 1980, los conflictos jurídicos que involucran pueblos indígenas han desbordado los límites del Estado Nación, porque los pueblos indígenas no solo se relacionan con problemas de carencia de protección del Estado, sino también con la globalización- contra empresas multinacionales, megaproyectos, organizaciones financieras y organizaciones no gubernamentales, que se han debatido en el seno del sistema Interamericano con la Corte Interamericana de Derechos Humanos y la OIT. Sin embargo, en el Sistema Internacional de Derechos Humanos no existen mecanismos judiciales para la resolución de dichos conflictos, tampoco la Corte Internacional de Justicia provee de un diseño judicial para los casos entre indígenas o colectividades contra los Estados. En el caso de la Corte Interamericana de Derechos Humanos ${ }^{7}$, accede a

7 Se ha proyectado que existen los siguientes casos se van a revisar con detenimiento: CIDH y la Comisión Interamericana de Derechos Humanos: los Indígenas Guahibos vs. Colombia (1970), La Tribu indígena Ache vs. Paraguay (1974), Yanomamis vs. Brasil (1980), Indígenas MisKitos vs. Nicaragua (1984), Aloeboetoe vs. Surinam presentado a la Comisión en (1988), Comunidad Mayagna (Sumo) Awas Tingni vs. Nicaragua (1995), Comunidades indígenas Enxet y Kaleyphapopyet-Riachito vs. Paraguay (1997), Comunidades Indígenas Mayas vs. Belice (1998), Comunidad Yaxye Axa del Pueblo Enxet-Lengua vs. Paraguay (2000) y La organización Yabti Tasba Masraka Nanih Asia Takanka (YATAMA) vs. Nicaragua (2001). En algunos casos se ha ordenado por parte de la CIDH medidas de protección a los pueblos indígenas como también en el caso de el caso de Saramaka versus el Estado de Surinam es una sentencia interpretativa y vinculante para todos los Estados miembros de la CIDH. 
conocer casos de los pueblos indígenas pero con ciertas restricciones: cuando el Estado ha aceptado los protocolos o donde los Estados partes han reportado obligaciones bajo los protocolos.

La evaluación de escenario de justicia internacional registrada por Naciones Unidas (2009, p. 223), establece que las decisiones de estos órganos de tratados de derechos humanos no son vinculantes o exigibles y con frecuencia son ignoradas por los Estados infractores. Por lo tanto, los esfuerzos indígenas en estos foros no han tenido resultados significativos en la resolución de conflictos. Como tampoco, la experiencia no ha sido alentadora en la forma como se resuelven los conflictos entre el Estado y los pueblos indígenas, tal como lo expresa Martínez, M., (1999, p. 196):

En prácticamente todos los casos, tanto en América Latina y en otras regiones mencionadas anteriormente, el establecimiento legal se puede ver que sirve como una herramienta eficaz en el proceso de dominación. Juristas (con sus elaboraciones conceptuales), las leyes nacionales (con su imperatividad, tanto en la metrópoli y en las colonias), el poder judicial (sujeto a la "estado de derecho"), el derecho internacional por un lado (su cumplimiento asegurado por medios militares) y los tribunales internacionales (sobre la base del derecho internacional vigente) estaban todos presentes para "validar" jurídicamente el saqueo organizado en las distintas etapas de la empresa colonial.

Esa evaluación histórico-jurídica va acompañada, con la tipología de medidas de protección que establecen los Estados para los derechos de los pueblos y comunidades étnicas. Por ejemplo, los Estados que consagran los derechos indígenas a nivel constitucional, como el caso de Colombia, la protección de los pueblos indígenas y comunidades étnicas es débil ${ }^{8}$. Primero la presencia estatal es débil por lo cual no ha podido implantar políticas diferenciales para la atención de sus necesidades básicas. Tampoco, el Estado Colombiano ha podido proteger los pueblos indígenas contra ataques de los grupos ilegales armados. Como mecanismo especifico de protección cuentan con la consulta previa ${ }^{9}$ como requisito de concesión de la licencia ambiental ${ }^{10}$ para los megaproyectos

8 Existen otras normas no menos importantes, que desarrollan la consulta previa y la participación de los pueblos indígenas en las decisiones susceptibles de afectarlos como son los Decretos 1396 y 1397 de 1996. Específicamente el Decreto 1397 establece la Comisión Nacional de Territorios Indígenas y la Mesa Permanente de Concertación entre el gobierno y los pueblos indígenas La primera, como su nombre lo indica, trata los asuntos relacionados directamente con el tema territorial y la segunda fija el procedimiento para concertar con los pueblos interesados los diferentes asuntos que puedan afectarles. Igualmente es necesario hacer referencia al Decreto 1320 de 1998, el cual fue expedido por el gobierno nacional para de reglamentar la consulta previa en materia de explotación de recursos naturales y que ha sufrido algunas vicisitudes. La Corte Constitucional se pronunció frente al mismo y en sentencia T-652 de 1998, suspendió la aplicación del mismo, cuando analizó el proceso de consulta con las comunidades indígenas Embera Katio del Alto Sinú, que hacían frente a la construcción y operación de una presa hidroeléctrica en su territorio ancestral, porque consideró que la aplicación del mismo resultaba a todas luces inconstitucional. También debe resaltarse como antecedente como por solicitud de la ONIC que es una organización de indígenas, se presento una reclamación ante la OIT por violación del Convenio 169 de 1989. El Comité de administración de la OIT consideró que "el proceso de consulta previa, tal como expresado en el Decreto núm. 1320, no está en conformidad con los artículos 2, 6, 7 y 15 del Convenio", igualmente pide al gobierno colombiano que "se modifique el Decreto 1320 de 1998 para ponerlo de conformidad con el Convenio, en consultación y con la participación activa de los representantes de los pueblos indigenas de Colombia, en conformidad con lo dispuesto en el Convenio" (Álvarez, 2004, p. xx)

9 Según Rodríguez, (2005, p. 15) la consulta previa es el derecho fundamental que tienen los pueblos indígenas de poder decidir sobre medidas (judiciales o administrativas) o cuando se vayan a realizar proyectos, obras o actividades dentro de sus territorios, buscando de esta manera proteger su integridad cultural, social y económica y garantizar el derecho a la participación. Concluye Rodríguez (2005, p. 36) que es un instrumento de ejercicio de la autonomía de los pueblos indígenas y comunidades negras, donde la interculturalidad debe ser un criterio fundamental para los procedimientos de consulta, ya que se articula el autogobierno con los proyectos de desarrollo nacional.

10 Sin embargo, las lecciones en el caso del pueblo U'wa contra Occidental de Colombia Inc en sede de tutela de su derecho a la consulta previa, tal como lo describe Sánchez (2001, p. 97) la Corte Constitucional en su sentencia SU-039 de 1997, no prohibió 
de infraestructura y minero-energéticos. Sin embargo, este mecanismo no soluciona los conflictos entre los derechos colectivos de los pueblos el derecho al desarrollo de las comunidades étnicas y las estrategias de desarrollo, es simplemente una herramienta que está supeditada a como se aplique y los procedimientos que se adopten con las comunidades ${ }^{11}$. Estos problemas desbordan la capacidad de autonomía, autodeterminación, gobierno propio y aplicación de su derecho propio de los pueblos indígenas.

Esta crisis humanitaria por violaciones de derecho internacional humanitario (DIH) de estas poblaciones, conllevó a que la Corte Constitucional Colombiana primero declarara la superación del estado de cosas inconstitucionales en la Sentencia T-025 de 2004, segundo, mediante el Auto 004 de 2009 para los Pueblos Indígenas y el Auto 005 de 2009 para los Pueblos Afrocolombianos, determinó que dichas poblaciones están en un grave riesgo de exterminio y cultural por causas no solo del conflicto armado sino también por encontrarse en tierras estratégicas por recursos naturales y por desprotección estatal. La Corte Colombiana en dichos Autos establece una serie de medidas: programas de garantías para atender y prevenir el desplazamiento forzado, planes de salvaguarda para los 34 grupos étnicos indígenas que están en grave riesgo y planes de atención diferencial para la población Afrocolombiana. No obstante, el cumplimiento de las órdenes de la Corte Constitucional es bajo ${ }^{12}$.

\section{Evaluación socio jurídica del funcionamiento territorial de la justicia indígena en Colombia. "entre Intromisión y defensa de la cosmovisión de los pueblos indígenas".}

Según el censo del Dane de 2005 "Visibilidad estadística de los grupos étnicos"13, la población indígena del país representa el 3.4\% (1.392.623 personas indígenas) de los cuales $49.51 \%$ son mujeres y el $50.48 \%$ son hombres. De los datos recopilados la población es bastante joven (de 0 a 14 años es el 39.54\%) y la esperanza de vida de los indígenas es inferior a la población colombiana.

La mayoría de la población indígena es rural (78.58\%) sin embargo, se ha venido incrementando la población indígena a las áreas urbanas por el desplazamiento, conflicto armado, precariedad económica en salud y nutrición y los efectos climáticos. Factores que también constituyen una amenaza para la sobrevivencia de los pueblos indígenas (PNUD, 2013, p.185).

Del censo del DANE está reportada la existencia de 87 pueblos indígenas en 29 departamentos del país donde el Amazonas y Vaupés tienen el mayor número de pueblos (tabla 1),

la entrada de la petrolera a su territorio, que era la protección que esperaba dicho pueblo, "la Corte se limitó a elaborar un fallo aplicable a cualquier comunidad indígena, no a los U'wa en particular".

11 No obstante, es claro que la situación en Colombia es problemática debido a que dichas comunidades ubicadas en territorio objetivo de los megaproyectos han sido desplazadas por paramilitares que apoyan la realización de dichos proyectos o por guerrillas que se oponen (Rico, 2009, p. 6)

12 El cumplimiento de las ordenes establecidas por la Corte Constitucional para los grupos étnicos en Colombia ha sido baja (Garavito 2010) tampoco se ha hecho un seguimiento y acompañamiento técnico integral del Gobierno y los grupos étnicos involucrados, como tampoco la Corte Constitucional desde el año 2009 no ha vuelto a citar a reuniones técnicas (Entrevistas con la OPIAC y ONIC 2013). Asimismo, la Mesa de Concertación Indígena suspendió los diálogos con el Gobierno Santos por el incumplimiento de la Ley 1450 de 2011 en la acápite indígena y el Decreto Ley 4633 de 2011 que dicta medidas de asistencia, atención, reparación integral y de restitución de derechos territoriales a las víctimas pertenecientes a los pueblos y comunidades indígenas.

13 Cabe resaltar que el mencionado Censo no contó con la consulta previa y que puede presentar variaciones metodológicas como la no inclusión de información relevante a los pueblos indígenas (PNUD 2013,182) 
después siguen Guaviare, Putumayo y Caquetá. Resaltando que son los municipios con mayor pobreza multidimensional ${ }^{14}$ y presencia de grupos armados ilegales, FARC, ELN, Urabeños, rastrojos y ERPAC (CERAC, 2011).

De conformidad con artículo 246 de la Constitución Nacional de Colombia la Jurisdicción indígena funciona en el territorio indígena, en concordancia, el Decreto 1088 de 1993 que "regula la creación de las asociaciones de Cabildos y/o Autoridades Tradicionales Indígenas"15 la población indígena se encuentra organizada por resguardos. En Colombia el número oscila entre 720 resguardos (DANE, 2005) a 868 resguardos- comunidades en 251 municipios al 2013, pero se estima que tres cuartas partes de la población indigna no habita en resguardos legalmente constituidos (PNUD 2013, 188). La mencionada normatividad ha reconocido 292 organizaciones indígenas (ibíd., 193) y existen 2 organizaciones a nivel nacional la ONIC- Organización Nacional Indígena de Colombia y la OPIAC- Organización de los Pueblos Indígenas de la Amazonia Colombiana. Quienes también están participando en el fortalecimiento de la Jurisdicción Indígena.

Tabla 1. Pueblos Indígenas y etnias por regiones y departamentos.

\begin{tabular}{|c|c|}
\hline $\begin{array}{l}\text { Territoriales DANE } \\
\text { y departamentos }\end{array}$ & Pueblos indígenas o etnias \\
\hline \multicolumn{2}{|r|}{ Norte } \\
\hline Atlantico & Mokana. \\
\hline Cesar & Arhuaco, Kogui, Wiwa, Yuko, Jankuamo. \\
\hline La Guajira & Arhuaco, Kogui, Wayuu, Wiwa. \\
\hline Magdalena & Arhuaco, Chimila, Kogui, Wiwa. \\
\hline Sucre & Senú. \\
\hline \multicolumn{2}{|r|}{ Noroccidental } \\
\hline Antioquia & Embera, Embera Chamí, Embera Katío, Senú, Tule, Wauman. \\
\hline Córdoba & Embera, Katío, Senú. \\
\hline Chocó & Embera, Embera Chamí, Embera Katío, Tule, Waunan. \\
\hline \multicolumn{2}{|r|}{ Nororiental } \\
\hline Arauca & Betoye, Chiricoa, Hitnu, Kuiba, Piapoco, Sikuani, U’wa. \\
\hline $\begin{array}{l}\text { Norte } \\
\text { de Santander }\end{array}$ & Barí, U’wa. \\
\hline Santander & (U’wa), Guanes. \\
\hline
\end{tabular}

Continua tabla...

14 El IPM es un índice desarrollado por Alkire y Foster $(2007,2011)$ de la Universidad de Oxford que fue adaptado por DNP para Colombia, incluyendo cinco dimensiones: condiciones educativas del hogar, condiciones de la niñez y la juventud, salud, trabajo, y acceso a los servicios públicos domiciliarios y las condiciones de la vivienda.

15 Este decreto ha impuesto la forma organizativa a los pueblos indígenas lo que también ha generado traumatismos, porque cualquier cambio que se haga en sus organizaciones tienen que "venir a Bogotá" y es un impedimento para formar gobiernos propios (Muñoz 2013) 


\begin{tabular}{|c|c|}
\hline $\begin{array}{l}\text { Territoriales DANE } \\
\text { y departamentos }\end{array}$ & Pueblos indígenas o etnias \\
\hline \multicolumn{2}{|r|}{ Central } \\
\hline Boyacá & U’wa, Muisca. \\
\hline Caquetá & $\begin{array}{l}\text { Andoke, Coreguaje, Coyaima, Embera, Embera Katío, Inga, } \\
\text { Makaguaje, Nasa, Uitoto. }\end{array}$ \\
\hline Casanare & $\begin{array}{l}\text { Amorúa, Kuiba, Masiguare, Sáliba, Sikuani, Tsiripu, Yaruros, } \\
\text { U'wa. }\end{array}$ \\
\hline Cundinamarca & Muisca. \\
\hline Huila & Coyaima, Dujos, Nasa, Yanacona. \\
\hline Meta & $\begin{array}{l}\text { Achagua, Guayabero, Nasa, Piapoco, Sikuani, Andoke, barasana, } \\
\text { Bora, Cocama, Inga, Karijona, Kawiyarí, Kubeo, Letuana. }\end{array}$ \\
\hline Amazonas & $\begin{array}{l}\text { Makuna, Matapí, Mirańa, Nonuya, Ocaina, Tanimuka, Tariano, } \\
\text { Tikuna, Uitoto, Yagua, Yauna, Yukura, Yurí. }\end{array}$ \\
\hline Guainía & Kurripako, Piapoco, Puinave, Sicuani, Yeral. \\
\hline Guaviare & $\begin{array}{l}\text { Desano, Guayabero, Karijona, Kubeo, Kurripako, Nukak, Piaroa, } \\
\text { Piratapuyo, Puinave, Sikuaní, Tucano, Wanano. }\end{array}$ \\
\hline Vaupés & $\begin{array}{l}\text { Bará, Barasana, Carapana, Desano, Kawiyarí, Kubeo, Kurripako, } \\
\text { Makuna, Nukak, Piratapuyo, Pisamira, Siriano, Taiwano, } \\
\text { Tariano, Tatuyo, Tucano, Tuyuka, Wariano, Yurutí. }\end{array}$ \\
\hline Vichada & Kurripako, Piapoco, Piaroa, Puinave, Sáliba, Sikuane. \\
\hline \multicolumn{2}{|r|}{ Centro-occidental } \\
\hline Caldas & Cañamono, Embera, Embera Chamí, Embera Katío. \\
\hline Risaralda & Embera, Embera Chamí. \\
\hline Tolima & Cayaima, Nasa. \\
\hline \multicolumn{2}{|r|}{ Sur-occidental } \\
\hline Cauca & $\begin{array}{l}\text { Coconuco, Embera, Eperara Siapidara, Guambiano, Guanaca, } \\
\text { Inga, Nasa, Totoró, Yanacona. }\end{array}$ \\
\hline Nariño & Awa, Coreguaje, Eperara Siapidara, Inga, Kofán, Pasto. \\
\hline Putumayo & $\begin{array}{l}\text { Awa, Coreguaje, Embera, Embera Katío, Inga, Kamentsa, Kofán, } \\
\text { Nasa, Siona, Uitoto. }\end{array}$ \\
\hline Valle del Cauca & Embera, Embera Chamí, Nasa, Waunan. \\
\hline
\end{tabular}

Fuente: DANE 2007.

Para el funcionamiento de la Jurisdicción Indígena se limita a la competencia territorial, por lo tanto, el funcionamiento de esta justicia se compone por los criterios de temáticas y la autoridad, teniendo en cuenta que para el Estado Colombiano y para la Justicia formal- Rama Judicial, es lo que establece el artículo 246 de la Constitución Política de Colombia. Es decir las temáticas que atiende la jurisdicción indígena, son las que pueden resolver las autoridades de los pueblos 
indígenas que son las que ejercen las funciones jurisdiccionales dentro de su ámbito territorial, definidas dentro de conformidad con sus propias normas y procedimientos, siempre que no sean contrarias a la Constitución y leyes de la República. Pero esta definición es miope desde la Ley de Origen y la misma dinámica de los grupos indígenas en las sociedades complejas postmodernas con presencia de grupos ilegales armados que promueven conductas ilegales en las áreas donde están ubicados.

Las temáticas de la jurisdicción indígena superan el concepto de "leyes de la Republica" porque la Ley de Origen proviene de la cosmogonía y cosmovisión ancestral de cada pueblo, regula temas espirituales, con la Madre Tierra, con los animales, ríos, animales, etc., y la forma como se solucionan son impensables desde el positivismo jurídico. Por lo tanto, no se pueden caracterizar las temáticas de manera general o categorías universales para todos los grupos étnicos, porque estas dependen de cada pueblo indígena. La compilación de temáticas "para que lo entiendan los no indígenas" dependerá exclusivamente de lo que cada pueblo decida en ejercicio de su autodeterminación y autogobierno (Teteye 2013; Gatian, 2013; Muñoz, 2013).

De la misma forma, la ley de origen supera "normas y procedimientos y sanciones" y esta definición ha creado problemas en los pueblos indígenas. En la configuración de la Jurisdicción Especial Indígena como creación constitucional de 1991, conllevó a que algunos pueblos indígenas "se llenaran de papeles" de Reglamentos Internos hecho por abogados con una visión foránea. Por lo cual, muchos casos que resolvían no tenían que ver con la Ley de Origen, esto creó un sincretismo jurídico y una intromisión ya que varias autoridades gubernamentales torpemente les exigían a los pueblos indígenas reglamentos internos para aplicar su derecho propio. En algunos casos el "debido proceso" de un reglamento interno llevaba a decisiones contrarias para la comunidad (Muñoz 2013) ${ }^{\mathbf{1 6}}$.

Segundo quienes ejercen la justicia en los pueblos indígenas no es homogéneo para todos los pueblos, en unos casos son las autoridades tradicionales, los líderes, los médicos tradicionales, las organizaciones indígenas, los Cabildos, las Asambleas, los capitanes, los thewalas, los sabedores, y los Taitas; se encontró que entre quienes ejercen la justicia hay algunos que dan consejo, otros que castigan, y otros que repararan las almas. O la autoridad está dispersa en la comunidad que tiene como núcleo la familia o el clan y los problemas se solucionan según esa escala jerárquica (Teteye, 2013). Por lo tanto los tipos de decisión son prolíficas y se dan según la forma y poder de la autoridad.

Por otra parte, las autoridades tradicionales manejan todo lo material y espiritual, interpretan, y hacen cumplir la Ley de Origen mediante procesos ancestrales, orientan y velan por el bienestar de los Pueblos indígenas y de la humanidad, para garantizar el equilibrio, el orden de la vida, del universo y de los Pueblos mismos. Apropian el saber colectivo, guardan las creencias y son la fuente de conocimiento indígena. Que como se expreso en el acápite anterior, los conflictos

$16 \mathrm{Al}$ respecto Muñoz comentó el problema de un indígena en una comunidad del Resguardo Mistratoi y Pueblo Rico Embera del Rio sanjuán. Frente a una tutela por indígena que había cometido varios crímenes y reiteradamente por lo cual el castigo determinado en reglamento interno no servía. Cuando la comunidad decidió enviarlo a la cárcel, el indígena tutelo que se le juzgara por el reglamento Interno a lo cual la Corte Constitucional accedió. Claramente en esta situación la comunidad se vio afectada y su reglamento interno no resolvió la situación de conformidad con Ley de Origen. 
que se dan en los territorios indígenas están afectando su capacidad de autogobierno y aplicación de la ley de origen.

Es fundamental para el Estado la protección y aplicación de la Ley de origen por parte de los pueblos indígenas: 1) Porque es una parte integral de la estructura social y la cultura de un pueblo; 2) porque junto con la lengua, constituye un elemento básico de identidad étnica; 3 ) porque la naturaleza de este derecho consuetudinario condiciona las relaciones entre el Estado y los pueblos indígenas; $y, 4)$ porque repercute en la forma en que estos pueblos gozan o carecen de derechos (tanto individuales como colectivos). Y es tal su importancia que "constituye uno de los elementos de preservación y reproducción de las culturas indígenas en el continente. Y por el contrario, su desaparición contribuye, a su vez, a la asimilación y al etnocidio de los pueblos indígenas" (Stavenhagen, 1990, p. 27).

Sin embargo, es importante mencionar que como característica de la Jurisdicción Especial Indígena en Colombia, este se permea por las particularidades de los sistemas de solución de conflictos presentes en Colombia. Los sistemas que entran en juego son el segmentario, el de autoridades comunales permanentes, los religiosos (incluyendo no sólo a la iglesia católica sino a las sectas protestantes y a los sistemas religiosos de comunidades indígenas, afroamericanas y campesinas) y los grupos armados (incluyendo no sólo a la guerrilla y al narcotráfico sino al ejército y a la policía cuando estos se desvían de sus funciones institucionales) y los sistemas de compensación directa (reparación o cobro de sangre) (Perafán, 1995, p. 22) ${ }^{17}$.

Hay un caso interesante en la Jurisdicción Especial Indígena que es una forma indígena que se ha adaptado a ciertos elementos del derecho formal colombiano, que es el Tribunal Superior

17 Sistema segmentario: Se caracteriza por la aparición de autoridades dependiendo de la posición de las partes en conflicto. Las autoridades no son permanentes, ni corresponden las mismas para un tipo determinado de comportamiento. No existe pues competencia sino una jurisdicción general de tipo personal, en el sentido en que la autoridad interviene cuando una persona que pertenece al grupo bajo su jurisdicción es parte en el conflicto. Esta jurisdicción puede catalogarse como de parentesco, en cuanto la pertenencia al grupo pasa por las reglas específicas del parentesco de cada cultura. Se denomina segmentario por dos razones; la primera, porque las comunidades están organizadas socialmente en segmentos: de la familia nuclear a la extensa, del linaje al clan, de clan a la tribu correspondiendo a cada uno de estos segmentos autoridades específicas. La segunda, porque este sistema se activa dependiendo de la localización de las partes dentro del conflicto. La autoridad entonces, asume su competencia con el surgimiento del conflicto mismo y la ejerce dentro de los límites temporales del procedimiento de manera exclusiva (Perafán, 1995, 23). Sistema de autoridades comunales permanentes: Por fuera del sistema segmentario, muchas comunidades han llegado a construir la institución de las autoridades centralizadas. En general, esta construcción obedece a dos razones: a la respuesta a procesos de complejidad en el desarrollo social o como reacción a situaciones de influencia externa. Estas autoridades cumplen funciones jurisdiccionales, aunque su actuación está restringida al funcionamiento del sistema político segmentario, en la base, y a su coordinación con el sistema nacional. La baja cobertura jurisdiccional de estas autoridades, se debe a que su función original no es de orden judicial sino administrativa (Perafán, 1995, 24). Sistema religioso: Sucede en muchas oportunidades, que a falta de un consenso, se recurra a la opinión de una persona o grupo de personas que tengan la calidad de detentadores del conocimiento mágico o de representantes de una institución religiosa. La intervención de autoridades religiosas puede trascender estas funciones de consulta de segunda instancia y pasar a las de autoridad con competencia para decidir. Existen límites entre lo mágico y lo religioso, entre el shamanismo y el sistema shamánico o la religión en el sentido en que para estos sistemas la simple actividad de tratamiento de enfermedades del curandero deviene en una práctica en la cual el sistema, shamánico o religioso, establece reglas de comportamiento, no solo espiritual, sino para la vida cotidiana (Perafán, 1995, 26). Sistema de compensación directa: Este sistema opera a la manera de paso previo o posterior al funcionamiento de la jurisdicción. Se trata de la relación entre los grupos de pertenencia de las partes en conflicto, en la búsqueda de una compensación a través de la cual puede dirimirse el conflicto. En estas compensaciones, resultado de transacciones, no existe una autoridad que emita fallo alguno. Es también característica de este sistema el que las ofensas, cualquiera que éstas sean, poseen un precio, la posibilidad de compensarlas con bienes y servicios, que excluyen la pena personal. El sistema de compensación directa no es técnicamente una jurisdicción, en cuanto es un sistema de transacción (en el previo) o de cobro unilateral (en el posterior), en el cual no existe autoridad, juicio, ni fallo alguno; sin embargo es un sistema difundido para el tratamiento de los conflictos (Perafán, 1995, 28-30). 
Indígena del Tolima ${ }^{18}$, institución judicial creada por el Consejo Regional Indígena del Tolima para fortalecer la administración de justicia al interior de sus territorios y resolver múltiples inconvenientes que se presentaban, ya sea al interior y entre los cabildos de la zona, o entre éstos y los funcionarios pertenecientes al sistema judicial nacional (jueces y fiscales encargados de la justicia ordinaria) y respondió a la necesidad de atacar la impunidad que se estaba generando, debido a que las autoridades indígenas desconocían sus deberes como administradores de justicia y por tanto mostraban falta de compromiso con la aplicación de justicia al interior de las comunidades (Ariza, 2010) También el Tribunal Superior Indígena del Tolima fue una forma de contrarrestar demandas laborales de indígenas a los Cabildos en juzgados laborales ordinarios (Muñoz, 2013).

Otro criterio para determinar la Jurisdicción Especial Indígena, para superar las nociones de autoridad y territorio, es lo que plantea Sánchez (2014, pp. 98-99):

Los "indios" han sido conocidos como seres cuya identidad ontológica está definida por nacimiento o por portar determinadas características. Pero no son pensados y tratados como seres en devenir cuya identidad no es el mantenimiento de algo inmanente y estático, sino que son invención permanente de identidad en relación tanto al propio mundo como al externo.

Por lo tanto un criterio determinante es la pertenencia étnica aceptada en la Tutela T-496 de 1996. Este indicador debe también entenderse en complemento con el indicador territorial. Es obvio, que la Jurisdicción Especial Indígena opera en los territorios indígenas. Sin embargo, los territorios indígenas se ubican recursos para la minería o áreas para cultivos ilícitos lo que fomenta la presencia de actores externos - como los mineros ilegales- y grupos ilegales que generan grandes problemas a la Jurisdicción Indígena en su la aplicación de la ley de origen bajo el entendido que ésta también regula las relaciones con la madre tierra ${ }^{19}$.

\section{Evaluación socio-jurídica de la relación ente la justicia indígena, la Jurisdicción Ordinaria y Constitucional.}

\section{Coordinación con la Jurisdicción ordinaria}

Este indicador es complementario al indicador de funcionamiento de la Jurisdicción Especial Indígena, por que el mandato constitucional establece que la Jurisdicción Indígena debe estar en coordinación con el sistema judicial nacional (artículo 246).

Con respecto a la Ley de Coordinación han sido presentados al Congreso de la República por el trámite correspondiente, tres proyectos, todos por iniciativa del senador Jesús Piñacué. En orden cronológico, el primero y el segundo fueron presentados en Cámara y el tercero en el se-

18 El Tribunal está compuesto por tres miembros principales y tres suplentes, que son líderes indígenas con suficiente experiencia e idoneidad organizativa, social y política. Según los Estatutos del CRIT, los seis miembros deben tener conocimientos sobre legislación indígena y JEI y no tener antecedentes penales, excepto delitos culposos. Son elegidos por el Congreso Regional Indígena para un período de cuatro (4) ańos, con posibilidad de ser reelegidos por una sola vez

$19 \mathrm{Al}$ respecto cuando es un proyecto del Estado Colombiano, se debe surtir la consulta previa que es un derecho fundamental de los pueblos indígenas, pero la jurisdicción especial indígena no opera por cuanto el interés nacional y la utilidad pública son limitantes de la autonomía indígena. 
nado. Los proyectos se distinguen así: Proyecto número 003 de 2000 Cámara; Proyecto número 029 de 2001 Cámara; Proyecto número 035 de 2003 Senado (Álvarez, 2004) Pero esto refleja que no hay una voluntad política desde el Estado y los pueblos indígenas. Para qué una coordinación? Bajo el entendido que varios pueblos indígenas ve esta situación como un vasallaje del Estado, donde éste no tiene en cuenta sus intereses y no lo ven como una prioridad (Ariza, 2010, p. xx) y es completamente innecesaria la coordinación cuando la aplicación de la ley de origen es eficaz ${ }^{20}$.

En contraste con lo anterior, el Consejo Superior de la Judicatura en diferentes espacios ha manifestado que "cumple" el mandato constitucional de fortalecer la democracia de participación y el pluralismo político, ideológico y cultural, así como fortalecer el pluralismo territorial que se construye sobre el respeto a los resguardos, a los territorios y a los lugares sagrados de las poblaciones indígenas.

En igual forma fomenta el conocimiento de la jurisprudencia de los pueblos indígenas, la construcción de sus propias escuelas judiciales, la elaboración de un mapa de identificación de los territorios donde tienen asiento las distintas culturas y los distintos sistemas judiciales indígenas; además, se quiere que en este proceso se expida, de manera concertada una ley de coordinación que permita que la Fiscalía, el Instituto Nacional Penitenciario y Carcelario, los jueces, las Altas Cortes y en fin todos los operadores de justicia que puedan colaborar y trabajar de manera coordinada para evitar desgastes y desconocimientos inútiles.

(Álvarez 2004, p. 50).

Al 2013 este estudio exploratorio encontró primero que no se tuvo un acceso a mapas de identificación de los territorios del Consejo Superior de la Judicatura, se encuentra son los generales del censo del DANE de 2005. Tampoco se ha logrado la ley de coordinación. Se menciona que la principal estrategia de coordinación entre la Jurisdicción Ordinaria y Jurisdicción Especial Indígena es lo que realiza la Sala Administrativa de la Rama Judicial de Colombia, que coordina un proceso de fortalecimiento de escuelas de derecho propio en solo 28 pueblos indígenas de los 87 pueblos reconocidos ${ }^{21}$. Es decir la coordinación de apoyo de la Rama Judicial no alcanza ni el 50\% de la Jurisdicción Especial Indígena entendida como la que se aplica en los territorios indígenas (tabla 2).

20 Muchos conflictos que se tratan en la jurisdicción indígena "quedan arreglados para siempre", pues en el campo de la jurisdicción mágico-religiosa, se considera que el método de "devolver el mal" es lo suficientemente eficaz como para que un determinado conflicto llegue a un punto de "no retorno" (Perafán, Azcárate y Zea, 2000, pp. 334-335).

21 Como lo expresaron Teteye y Muñoz de la OPIAC, existen "pueblos no contactados" que no están dentro de las estadísticas oficiales. Como los que habitan en el parque Yuri, en el eje del río Puré. Tampoco hay reconocidos otros grupos por la institucionalidad por su territorio intangible. 
Tabla 2. Pueblos Indígenas y ubicación geográfica del programa de Fortalecimiento de Escuelas de derecho propio de la Rama Judicial de Colombia.

\begin{tabular}{|c|c|}
\hline PUEBLO & UBICACIÓN \\
\hline Pueblo Huitoto & Caquetá- La Chorrera \\
\hline Pueblo Pijao & Tolima \\
\hline Pueblo Wayuú & Guajira \\
\hline Pueblo Achagua & Meta \\
\hline Pueblo Piapoco & Meta \\
\hline Pueblo Sicuani & Meta \\
\hline Pueblo Sáliva & Meta \\
\hline Pueblo Guambiano & Cauca \\
\hline Pueblo Los Pastos & Nariño \\
\hline Pueblo Nasa-ACIN & Cauca \\
\hline Pueblo Zenú & Cordoba-Sucre \\
\hline Pueblo Kankuamo & Sierra Nevada de Santa Martha \\
\hline Pueblo Embera Dovidá & Choco \\
\hline Pueblo Tikuna & Amazonas \\
\hline Pueblo Arhuaco & Sierra Nevada de Santa Martha \\
\hline Pueblo Embera Chami & Risaralda \\
\hline Pueblo Muiname & La Chorrera Amazonas \\
\hline Pueblo Wiwa & Sierra Nevada de Santa Martha \\
\hline Pueblo Yanacona & Huila \\
\hline Pueblo Kamentsá & Putumayo \\
\hline Pueblo Cubeo & Vaupés \\
\hline Pueblo Tukano & Vaupés \\
\hline Pueblo Ocaina & La Chorrera Amazonas \\
\hline Pueblo Yagua & Amazonas \\
\hline Pueblo Bora & La Chorrera Amazonas \\
\hline Pueblo Tule & Choco-Antioquia \\
\hline Pueblo Cocama & Amazonas \\
\hline Pueblo Kogui & Sierra Nevada de Santa Martha \\
\hline
\end{tabular}

Fuente: Respuesta requerimiento de información UDAEOF13-2982 Rama Judicial del Poder Público.

Sin embargo, con respecto a ese panorama se encuentran casos registrados donde algunos pueblos indígenas son los que promueven la coordinación con la Jurisdicción Ordinaria. Como son los Embera-Chamí donde envía los casos a la justicia ordinaria cuando el cabildo presume la existencia de peligro para una de las partes del conflicto y se teman venganzas, o porque presente dificul- 
tades en la captura del sindicado o cuando no se logra esclarecer una investigación; de esta manera se evita que los interesados "denuncien al cabildo por inactividad" (Perafán, Azcárate y Zea, 2000, pp. 176-177). El otro caso es el del pueblo Nasa ya que los resguardos son municipios, en los que se experimenta la coexistencia de dos autoridades que desempeñan las mismas funciones en una misma casa (ACIN, 2005, p 46). O el caso del Tribunal Superior Indígena que tiene Protocolo de Coordinación Interjurisdiccional2.

Cabe mencionar que el Consejo Superior de la Judicatura viene construyendo una "Jurisprudencia Indígena” disponible en internet donde no solo integra lo interno, sino la relación con la jurisdicción ordinaria. Es decir es una jurisprudencia desde lo Estatal no desde lo Indígena.

Los criterios que se tuvieron en cuenta para realizar la compilación y selección de fallos y decisiones de la Jurisdicción especial indígena 1980-2006 fueron: por temas entre otros: autoridades, representación, educación resistencia civil y paz, territorio, linderos y recursos naturales, en relación con las decisiones de las autoridades indígenas. Una segunda parte abordó los fallos de la jurisdicción nacional, principales sentencias de la Corte Constitucional, decisiones de la Corte Suprema de Justicia, Consejo de Estado y Sala Jurisdiccional Disciplinaria (Rama Judicial del Poder Público, 2013).

$\mathrm{Al}$ indagar sobre la jurisprudencia indígena, los representantes de la ONIC y OPIAC, manifestaron que existe la jurisprudencia indígena, que es la forma como se usa cotidianamente la Ley de origen, dado que su uso es consuetudinario. Obviamente, también se debe tener en cuenta la Jurisprudencia Constitucional en la protección de los pueblos indígenas.

Sin embargo, como lo manifiesta Ariza (2008):

Compartimos entonces con la doctrina nacional y extranjera que la definición de las reglas de juego sobre los límites y competencia de la Jurisdicción Especial Indígena no es asunto que deban decidir los tribunales. Esas reglas deben construirse en escenarios de diálogo intercultural, en consulta interna y externa con cada pueblo. Sin embargo, el contenido esencial de los derechos no es discutido con los respectivos pueblos, pese a los esfuerzos de la Corte Constitucional, a los peritazgos antropológicos y a oír en audiencia pública a diferentes estamentos. Adicionalmente, aún no está claro en estos diecisiete años de producción jurisprudencial el núcleo central de valores que la Corte suscribe en cada cultura; hay de hecho en la jurisprudencia revisada asomos de respeto intercultural pero el centro de la complejidad está en el límite de los diferentes derechos encontrados tanto al interior de los pueblos como en la sociedad mayor. Resolver esta dicotomía implica una reinterpretación de lo ya dicho y ubicar, o mejor, encontrar una tesis que no sea ecléctica siempre.

(Ariza, 2008, pp. 77-78)

$22 \mathrm{El}$ protocolo tiene como propósito hacer una coordinación verdaderamente efectiva y eficaz entre las dos jurisdicciones. Este protocolo es un instrumento que nace de la experiencia con la Casa de Justicia Regional del sur del Tolima y denota un grado de avance práctico y concreto en el tema por parte de los miembros del Tribunal y de las instituciones que aceptan el protocolo (Ariza, 2010). 


\section{Relación entre la Jurisdicción Ordinaria. "Una relación poco amigable”}

La relación de la jurisdicción ordinaria con la jurisdicción especial indígena está influenciada en que concibe a los pueblos indígenas como incapaces para juzgar delitos graves y control de la impunidad. Hay una densificación de lo penal para todo en la justicia indígena de cuales con los castigos validos (Muñoz 2013). Como lo definió Muñoz (2013) es una "relación poco amigable."

Prueba de ello ocurre en Colombia con la Sala Jurisdiccional Disciplinaria del Consejo Superior de la Judicatura, que en los últimos años ha dirimido conflictos de competencia entre la jurisdicción ordinaria y la jurisdicción indígena, retomando, en la mayoría de asuntos sometidos a su estudio, la jurisprudencia de la Corte Constitucional, pero con una interpretación de la misma en la que reiteradamente se afirma que los pueblos indígenas no tienen competencia ni capacidad para asumir el juzgamiento de indígenas que cometan delitos que atenten contra el orden público (subversión), ni tampoco asuntos referidos al tráfico de estupefacientes.

Ariza, 2010, p. 86.

Según Muñoz (2013) de los conflictos de competencia, la Sala Disciplinaria del Consejo Superior de la Judicatura, por ejemplo de 37 casos solo 4 ha aceptado la Jurisdicción Especial Indígena. De la misma forma como lo comenta Ariza (2010) en ningún caso:

La Sala Disciplinaria se auxilió de peritazgo antropológico alguno, ni consultó a la comunidad de los respectivos "sindicados": este tribunal acudió únicamente a la jurisprudencia constitucional" (...) "Estas aplicaciones denotan que la la Sala Disciplinaria del Consejo Superior de la Judicatura, desconoce de los avances en materia intercultural y de las propias reglas que la Corte Constitucional fijó y que la misma Sala invoca casi siempre equivocadamente. De las sentencias analizadas, encontramos entonces que en un 70 por ciento esta Sala niega la competencia de la jurisdicción indígena. Ello ocurre, como se ha explicado, por una interpretación bastante restringida, monista y sobre todo, por el exacerbado positivismo de parte de esta colegiatura.

Ariza, 2010, p. 87.

Sin embargo, por las entrevistas realizadas con la ONIC y OPIAC (2013) se encuentra que por parte de las organizaciones indígenas se ha gestionado una coordinación con el INPEC para que los indígenas (aproximadamente 72 indígenas de las Amazonas) estén en centros penitenciarios cercanos a sus comunidades. La coordinación con la Fiscalía General de la Nación en las regiones en la mayoría de los casos no respeta los territorios indígenas como la jurisdicción indígena y siempre plantea la situación como "obstrucción a la justicia" especialmente donde los indígenas no son beligerantes. Esto no pasa en el Cauca. La Fiscalía Regional respeta la autoridad indígena porque que sus funcionarios "pueden recibir el cepo" (Muńoz 2013) "Las instituciones crean es más problemas en los territorios indígenas" (Gaitán 2013).

Para los indígenas ven como una profunda dificultad para la Jurisdicción Especial Indígena “que los jueces se burlen de la justicia propia” (Gaitán 2013).

Los jueces ordinarios manifiestan que las autoridades indígenas no tienen la capacidad suficiente para juzgar casos de importancia o más complejos. De acuerdo a su opinión, las autoridades indígenas deben limitarse simplemente a juzgar casos menores. A su modo de ver, las autoridades 
indígenas utilizan su propia jurisdicción sólo cuando las circunstancias lo ameriten, es decir, cuando buscan evadir la aplicación de la justicia ordinaria.

Ariza, 2010, p. 60.

\section{Relación entre la Corte Constitucional- "Entre el pluralismo unitario e igualitario"}

La relación entre la Corte Constitucional Colombiana y la Jurisdicción Especial Indígena por la carencia de ley de coordinación, la corte ha asumido esta coordinación a través de estudio de casos concretos por tutela, ha procurado establecer las reglas que guíen la interacción de la justicia oficial con la indígena (Ariza 2010) como también los límites de la autonomía de la Jurisdicción Indígena -Se podría decir que la Corte Constitucional ha definido la Jurisdicción Indígena en Colombia- De la misma forma, los pueblos indígenas acuden a la tutela para proteger sus derechos fundamentales colectivos imponiendo ordenes y obligaciones al Estado.

Primero, la Corte Constitucional ha reconocido que la Jurisdicción Especial Indígena tiene todas las potestades que tiene cualquier jurisdicción: notio, iudicium, imperium o coercio ${ }^{23}$. Sin embargo, según Ariza (2008), con respecto al conflicto de competencias.

La Corte ha tenido en estos años diferentes posturas frente a las decisiones de las autoridades indígenas. Entre las más destacadas citemos:

- Pedir que se repita el juzgamiento.

- Ordenar que se consulte de nuevo a la comunidad a ver si se repite o no el juicio y si no se repite, pasárselo a las autoridades judiciales ordinarias.

- Reconocer plenamente la decisión.

- Reconocer parcialmente la decisión y pedir revisión de la misma.

Lo normal en las tutelas concedidas en revisión por la Corte Constitucional -siempre a través del mecanismo de revisión-, es que ellas hayan sido negadas en las primeras instancias judiciales ordinarias. Incluso a veces -no siempre- estas instancias judiciales ordinarias han exhibido posturas un poco más abiertas que las de la Corte misma. No obstante, la Corte ha definido una línea en el tema, que tiene su culmen en la exigibilidad a las autoridades indígenas del cumplimiento del mínimo vital legal que se debe respetar por parte de ellas ${ }^{24}$.

Ariza, 2010, p. 76.

La jurisprudencia analizada respecto a la jurisdicción indígena y sus múltiples interpretaciones por parte de la Corte, deja ver que ésta ha llevado a una restricción de los derechos de los pueblos considerados tanto en lo referente a sujetos colectivos como a sujetos individuales. Estas múltiples interpretaciones conllevan el menoscabo de diferentes derechos de los pueblos indígenas, pero de hecho el más afectado a lo largo de estos ańos es el del ejercicio de la propia jurisdicción, porque

23 Esto es, la potestad para conocer los asuntos que le correspondan, incluyendo funciones operativas para citar a las partes, recaudar pruebas (notio); la potestad para resolver los asuntos que conoce, siguiendo su propio derecho (iudicium), y finalmente, la potestad de usar la fuerza para hacer efectivas sus decisiones en caso de ser necesario. Ello comprende acciones que pueden restringir derechos, tales como ejecutar detenciones. (Ariza 2008)

24 Esto se unificó mediante sentencia SU-510 de 1998 sobre los criterios de divergencia en tutela llegando a la conclusión que no se afecte los derechos fundamentales de los miembros de la comunidad como límite de la autonomía de la Jurisdicción Indígena. 
a medida que pasa el tiempo se establece mayores limitantes que impiden a las autoridades indígenas administrar justicia. (Ariza 2008)

La Corte Constitucional Colombiana ha impuesto categorías universales occidentales a la Jurisdicción Indígena como el debido proceso para la aplicación de la Ley de Origen. Al respecto, no hay un consenso. Los pueblos indígenas tienen una cosmovisión y le darán un contenido diferente a la normatividad jurídica colombiana. Situación que también es contradictoria con diversas sentencias que han sostenido que la Jurisdicción Especial Indígena "no puede ser reglamentada, básicamente por dos razones: primera, se presume -y con razón-, que dentro de las tradiciones propias subyace de por sí una normatividad o reglamentación cultural; y, segunda, de hacerse eso, se atentaría contra la diversidad étnica y cultural del país”. (Ariza 2010).

Con respecto a la autonomía de la Jurisdicción Indígena, la Corte Constitucional ha determinado los siguientes criterios:

1. A mayor cohesión y autocontrol por parte del grupo y con el fin de asegurar la conservación de los usos y costumbres del grupo, se reconoce una mayor autonomía.

2. Los derechos fundamentales constituyen los mínimos jurídicos para la convivencia y bajo ningún supuesto podrán denegarse.

3. Las normas de orden público del derecho nacional priman sobre las normas de las comunidades indígenas siempre que protejan un valor constitucional de mayor peso que el principio de la diversidad étnica y la integridad del grupo indígena. No por la sola existencia de una ley contraria a las costumbres estas pueden ser desconocidas.

4. Los usos y costumbres indígenas priman sobre las normas dispositivas del derecho nacional.

Ariza 2010, pp. 93-94.

Como lo expresa Sánchez (2004) para la Corte Constitucional colombiana no ha sido fácil el manejo sobre cuestiones multiculturales y son diversas las interpretaciones de la tensión entre diversidad y unidad cultural que existe al interior de la Constitución desde el liberalismo ${ }^{25}$ y multiculturalismo. La tutela puede ser un medio para el fortalecimiento de la etnicidad y la cultura. No se puede negar que por medio de la Tutela en Colombia se han querido acomodar las minorías culturales a los valores morales y políticos de la mayoría, pero para esto hay que honrar a los pueblos indígenas que procuran hacer justicia de manera rigurosa para resolver sus conflictos, en un contexto de pluralismo jurídico que trasciende los papeles de actores, actuaciones, aplicaciones técnicas y aplicaciones edificantes, y respetando como principio la interculturalidad, para coaccionar a sus sociedades particulares.

a. Realizar el pluralismo jurídico. Si el derrotero constitucional fue valorar la existencia de mundos culturales distintos y distribuir las competencias jurisdiccionales ordinarias con los jueces na-

25 La regla de que los valores básicos del liberalismo deben ser reconocidos por todas las culturas, la segunda indica que los derechos individuales pueden ser restringidos si hay evidencia de que este es el único medio disponible para evitar la desaparición de una cultura. Estos dos puntos de vista argumentan que al dar prioridad a las tradiciones morales y políticas de la mayoría se resuelve justamente el conflicto entre la cultura dominante y las minorías culturales. La única diferencia cultural que la Constitución reconoce y acomoda es entonces aquella producida por las varias interpretaciones del canon liberal. Como consecuencia, el Estado puede legítimamente invertir sus recursos en la transformación de cualquier tradición que se encuentre fuera de los límites del liberalismo (Bonilla, 2005, pp. 3-6). 
turales de los pueblos indígenas, es fundamental que esa metamorfosis también ocurra más allá de cada uno de los Si el derrotero constitucional.

b. Interculturalidad como principio. Los intercambios entre sociedades culturalmente distintas deben centrarse en la disposición a dar y a recibir, para generar equilibrio, porque este principio apunta a la construcción de sujetos socialmente competentes para el respeto y valoración de la diferencia.

La valoración de sí mismos, como pueblos indígenas, prospera dentro de esos pueblos en la medida en que las comunidades y cada uno de los comunitarios miembros se encuentren luchando por aumentar la comunicación, el fortalecimiento y defensa de los propios argumentos, rechazando los mecanismos internos o externos que los acallan.

Sánchez, 2008, p. 148.

Finalmente, como se evidenció en las entrevistas con la ONIC y la OPIAC, los grupos indígenas han logrado reivindicar la protección de sus derechos como pueblo frente a los problemas estructurales de la violencia y desplazamiento y las constantes violaciones al Derecho Internacional Humanitario. Por lo tanto, la Corte Constitucional Colombiana primero declarara el estado de cosas inconstitucionales en la Sentencia T-025 de 2004, segundo, mediante el Auto 004 de 2009, que ordenaron una serie de medidas: programas de garantías para atender y prevenir el desplazamiento forzado, planes de salvaguarda para los 34 grupos étnicos indígenas que están en grave riesgo y planes de atención diferencial para la población Afrocolombiana.

\section{Evaluación socio-política del e fortalecimiento institucional por parte del Estado colombiano y agencias internacionales a la Jurisdicción Especial Indígena.}

En complemento de los anteriores indicadores, por la lucha reivindicatoria de los pueblos indígenas para cumplir los fines del Estado Social de Derecho, pluricultural y pluriétnico, como también las ordenes que ha departido la Corte Constitucional (Auto 004 de 2009) para la protección de los derechos de los pueblos, donde es parte esencial la Jurisdicción Indígena como forma del derecho de la autodeterminación y autogobierno, se analizarán las diferentes políticas para el fortalecimiento de la Jurisdicción Indígena.

\section{Políticas del Estado Colombiano.}

Específicamente para la Jurisdicción Especial Indígena, actualmente la Sala Administrativa del Consejo Superior de la Judicatura, en virtud de las competencias otorgadas mediante la Constitución Política en el artículo 246, que le otorga la competencia para señalar la forma en que debe darse la coordinación de la Jurisdicción Especial Indígena con el Sistema Judicial Nacional, ha desarrollado su labor desde 5 líneas estratégicas: diagnóstico ${ }^{26}$, coordinación ${ }^{27}$, ca-

26 La Sala Administrativa realizó durante el año 2012 cinco (5) talleres regionales de diagnóstico, en donde se identificaron diferentes necesidades de las comunidades indígenas en materia de coordinación. Un taller especifico de diagnostico para la restitución de tierras de territorios colectivos.

27 Comisión Nacional de Coordinación de la Jurisdicción Especial Indígena y el Sistema Judicial Nacional. La Sala Administrativa, con el apoyo de la ONIC, diseño, convocó y organizó la Comisión Nacional de Coordinación, como "órgano e instancia permanente de interlocución, concertación, planeación, diseńo y seguimiento de las políticas públicas de la Rama Judicial en materia de Jurisdicción Especial Indígena”. Esta instancia fue creada mediante Acuerdo PSAA12-9614 de 2012. 
pacitación $^{28}$, fortalecimiento y difusión ${ }^{29}$. (Rama Judicial del Poder Público, 2013). En el año 2004 estuvo funcionando el "Programa Intercultural sobre Jurisdicciones Especiales Indígenas" o el "Programa de apoyo a la coordinación entre el Sistema Judicial Nacional y la Jurisdicción Especial Indígena”, auspiciados por organizaciones como la Unión Europea, el BID y la Agencia de Cooperación Internacional (ACCI) y en el marco de los cuales se ha contado con la participación de organizaciones de orden nacional de pueblos indígenas como la ONIC, pero también de miembros de diferentes pueblos indígenas, y de instituciones estatales como el Concejo Superior de la Judicatura, y el Ministerio de Justicia y del Interior.

No obstante, estos programas de la Rama Judicial no han logrado una coordinación amplia, empezando desde la Sala Disciplinaria, donde se evidenció en el anterior indicador que la Justicia Ordinaria se limita a aplicar la jurisprudencia constitucional y no aceptar la Jurisdicción Especial Indígena.

En temas de actual debate de la reforma a la Justicia y de presupuesto, no figura presupuesto especial para la Jurisdicción Especial Indígena. Desafortunadamente en los documentos de política pública a todo el sector Justicia no se encuentra un documento o línea específica para la Jurisdicción Especial Indígena. Por ejemplo, en el documento diseñado por el Departamento Nacional de Planeación "2019 Visión Colombia II Centenario. Garantizar una Justicia Eficiente”. Para la Jurisdicción Especial Indígena se referencia en la submeta para rediseńar los programas de formación y capacitación de operadores de justicia”.

El problema de presupuesto fue indicado como el factor de mayor dificultad por las organizaciones indígenas ONIC y OPIAC para fortalecer la figura de la Jurisdicción Indígena. Acompañado de la carencia de la voluntad política porque no ven crucial el multiculturalismo y el pluralismo jurídico como fin y valor del Estado Colombiano. También estas organizaciones criticaron el capital humano que están en las Instituciones del Ministerio Público, Fiscalía y Rama Judicial desconoce como interactuar con los pueblos indígenas creando mayores conflictos.

\section{Propuestas de Política desde los Pueblos Indígenas. "Si los indígenas mejoran sus condiciones de vida Colombia mejora."}

Las propuestas desde los pueblos Indígenas las presentan de manera holística, de defensa de sus derechos colectivos emanados desde la Constitución Nacional y desde los Tratados Internacionales. Además las propuestas van encaminadas primero garantizar la pervivencia física y cultural de los pueblos quienes afrontan situaciones difíciles y en algunos casos están en riesgo de extinción. Segundo, la articulación de los Planes de Desarrollo Territorial, los Planes de Ordenamiento

28 El Programa de Formación Intercultural de la Escuela Judicial Rodrigo Lara Bonilla adscrita a la Sala Administrativa, tiene como objetivo llevar a cabo unos procesos de capacitación intercultural entre autoridades indígenas y Jueces y Magistrados de la República con el fin de que se dé un proceso de sensibilización y conocimiento mutuo. Como producto de este Programa, la Sala cuenta actualmente con un Módulo de Formación Intercultural que se ha venido impartiendo, desde el ańo 2005, en talleres en donde participan tanto autoridades indígenas de la zona, como jueces y magistrados competentes.

29 Una coordinación de la oferta Judicial Nacional con la Jurisdicción Especial Indígena exige necesariamente unos sistemas jurídicos propios, lo que supone el apoyo y acompańamiento de las Escuelas de Derecho Propio de las 102 comunidades indígenas del país. 
Territorial y los Planes de Salvaguarda con algunos componentes de los Planes de Vida que sean considerados por los pueblos indígenas.

En el año 2010 en Colombia se realizó una propuesta presentada por los Indígenas para que este país cuente con un Plan Nacional de Desarrollo para la prosperidad, inclusión y respeto a la diversidad étnica y cultural del país, concebida como un Plan Integral de Permanencia y Pervivencia de los Pueblos Indígenas, propone un "Pacto de conservación y restitución del equilibrio de la madre tierra para el buen vivir" ${ }^{30}$. Este documento, es producto del ejercicio de consulta en las cinco macro-regiones en que están organizados los pueblos indígenas de Colombia, recogido en el espacio autónomo de la Mesa de Concertación (Gerardojumi 2010).

Este documento basado en la voluntad política del gobierno entrante con los 102 pueblos indígenas llegar a un convenio de respeto a los derechos de los pueblos indígenas para: la adopción de normas internacionales a la legislación interna del país, que protejan sus derechos, como la modificación de algunas normas vigentes para que permitan realmente el pleno goce de autonomía en los asuntos de gobierno para la administración de la salud, la justicia, la educación y el territorio (Gerardojumi 2010), situación que permite entender la posibilidad del reconocimiento y de un futuro desarrollo del derecho al Desarrollo de estas comunidades étnicas. Dicha propuesta Indígena aboga por el tránsito de un Estado Social de Derecho a Un Estado Plurinacional.

Las Organizaciones Indígenas de la ONIC y OPIAC, están trabajando en el fortalecimiento de Escuelas propias y modelos pedagógicos de Ley de Origen en los territorios Indígenas.

\section{Propuestas de Agencias Internacionales}

Se menciona que el Programa de Naciones Unidas para el Desarrollo está trabajando en ajustar los Objetivos del Desarrollo del Milenio para pueblos indígenas en Colombia. Los cuales se han establecido que es fundamental la protección y defensa del territorio indígena, la autodeterminación y gobierno propio, el desarrollo propio y buen vivir, la consulta previa y el rediseńo institucional del Estado.

Pero la evaluación del impacto de las políticas para y de los pueblos indígenas en Colombia, aunque se han hecho avances significativos de ubicación de problemas e indicadores, solo se han podido establecer programas de atención con un impacto muy bajo.

Pasados cuatros años ni siquiera la Corte Constitucional ha hecho un seguimiento al cumplimiento del Auto 004 de 2009, o ha hecho reuniones técnicas o ha llamado la atención al Estado del no cumplimiento de las medidas de protección a los pueblos indígenas.

Teyeye, 2013, comunicación personal.

30 Estos objetivos demandarán del Estado en su conjunto estrategias orientadas a: El mejoramiento de las condiciones de vida de las comunidades de los pueblos indígenas a partir de sus derechos y particularidades culturales y regionales, La reestructuración de sistema administrativo y de atención pública que el Estado presta a los pueblos indígenas creando un Ministerio de los Asuntos de los Pueblos Indígenas, asegurando la participación indígena en las decisiones que se adopten. La consulta y concertación de las acciones de bienestar y desarrollo que impliquen a las comunidades de los pueblos indígenas. El fortalecimiento de la capacidad social de los pueblos indígenas, sus autoridades y organizaciones para la gestión y decisión sobre las acciones de bienestar y desarrollo que los impliquen. 


\section{Conclusión}

El estudio realizado sobre la justicia indígena en Colombia, da como resultado que teóricamente y sociojurídicamente, la tipología del Sistema Jurídico Colombiano es que presenta elementos del Pluralismo de tipo unitario e igualitario (Hoekeman 1998). El pluralismo unitario es el aplicado por la Jurisdicción Ordinaria, que se reserva unilateralmente determinar la legitimidad y el ámbito de los demás derechos reconocidos por la jurisprudencia. El Pluralismo igualitario, que en algunos casos la Corte Constitucional Colombiana ha reconocido la validez de normas de los demás sistemas de derecho, como es la ley de origen de los pueblos indígenas como parte integral del orden legal nacional.

Segundo, en el sistema jurídico colombiano se entiende que la Jurisdicción Especial Indígena es la ley de origen que es sinónimo del derecho indígena como un sistema jurídico que se encuentra imbricado, entrelazado e influido por el sistema jurídico positivo, ya que muchas de las instituciones de éste -como las municipales, agrarias, electorales, de procuración e impartición de justicia- han sido impuestas y reapropiadas por los pueblos indígenas, incorporándolas a sus formas y estructuras de organización, como es el caso del Tribunal Superior Indígena del Tolima . Pese a esto, el sistema jurídico indígena tiene particularidades a distintos niveles, instancias legales y autoridades. Esto es lógico, ya que el sistema jurídico indígena es el resultado de la historia y cultura de cada pueblo y comunidad indígena en su contexto regional y estatal (Cruz, 2008).

La evaluación socio-jurídica de la Jurisdicción Indígena es que opera en la periferia y para un grupo poblacional minoritario, vulnerable y victima de continuas violaciones de derecho internacional humanitario. Por la presencia débil o inexistente del Estado Colombiano, en contraste, con la presencia fuerte de grupos armados ilegales por razones geoestratégicas en los territorios indígenas. Desafortunadamente están en peligro de extinción 32 pueblos indígenas, en consecuencia, el fortalecimiento de la Jurisdicción Indígena hace parte de una protección integral de los derechos humanos y de los derechos de los pueblos indígenas consagrados en la legislación nacional e internacional ratificada por Colombia.

Si bien, con la incorporación de la Jurisdicción Indígena Colombiana desde 1991, se ha avanzado en la reapropiación de las prácticas de justicia propia en todo el territorio nacional, se ha demostrado que el Estado Colombiano carece de voluntad política para garantizar el ejercicio pleno de la autonomía de los pueblos indígenas, pues no facilita recursos ni infraestructura para posibilitar los diversos planes de vida, o para hacer prácticas las decisiones colectivas de las comunidades y autoridades indígenas cuando se requiere garantizar la armonización y el equilibrio comunitario.

Asimismo la evaluación socio-jurídica de la Jurisdicción Especial Indígena adolece de problemas estructurales en su relacionamiento y reconocimiento por parte de las Instituciones del Estado desde el Ejecutivo, el Ministerio Público y la Rama Judicial. Sin embargo, los pueblos indígenas y su justicia están en la lucha de la sobrevivencia y resistencia por ser víctimas de los grupos ilegales que violan sus territorios, capturan a los jóvenes indígenas para el conflicto armado, o la minería ilegal o narcotráfico. Esto viene rompiendo todo el tejido social, ecosistemico y cosmogónico de los pueblos indígenas, por lo que se presentan los fenómenos de desplazamiento forzado por violencia, escases de tierras y alimentos y desintegración de familias y clanes indígenas. 
Es de resaltar que en el Sistema Jurídico colombiano existe la tensión entre la Ley ordinaria y el Derecho Propio. La formación jurídica en Colombia todavía no responde al pluralismo jurídico determinado en la Constitución Política de 1991, por lo cual se da prevalencia de la aplicación del derecho ordinario tras el desconocimiento del derecho propio de los pueblos indígenas. Sumado a esto, las instituciones gubernamentales que manejan asuntos con los pueblos indígenas no poseen políticas de trato diferencial.

En consecuencia por los problemas estructurales anteriormente mencionados, dan como resultado que el concepto de derecho propio y la Jurisdicción Especial Indígena, su discurso reivindicatorio, contenido y aplicación, es la expresión máxima de los pueblos indígenas, como resistencia y de protección de su supervivencia: es "un sistema cultural, con una trayectoria histórica, con una formación jurídica y con una configuración política” (Ariza 2010). Desde 1991 los grupos étnicos están reconstruyendo el Derecho Propio, rescatando su cosmovisión, identidad, fortalecen su cultura y la autonomía en el territorio de los pueblos indígenas. Como lo definieron la ONIC y OPIAC- Ley de origen no es más que el equilibrio entre el hombre y la naturaleza. Concepciones de mundo que se ve continuamente amenazada por el conflicto interno armado y por la falta de protección del Estado.

Otro resultado socio-jurídico es que la fuerza de la justicia entre los pueblos indígenas, para que tenga eficacia, debe estar centrada en el sujeto colectivo de derecho. La Jurisdicción Indígena y su relación con la Jurisdicción Ordinaria indican que se deben generar transformaciones que propicien nuevas formas para su fortalecimiento, ya que si el sistema jurídico se mantiene totalmente abierto o totalmente cerrado, desaparecería. Ello representa una lucha entre dos modelos socioculturales: el del individualismo, asentado en la idea liberal de libertad, y el del comunitarismo, como "sometimiento" del individuo para que sobreviva la sociedad. Debe entenderse también que esa lucha por la aplicación ejemplarizante y constructiva del derecho es simultáneamente la batalla por una sociedad que los vuelva cada día más posibles y maximice su vigencia (Sánchez, 2008).

Como propuesta a la triste realidad descrita en la investigación se propone que la sociedad colombiana y el Estado Colombiano, frente a la reivindicación de los pueblos indígenas y el fortalecimiento de la Jurisdicción Indígena, debe primero, garantizar materialmente el disfrute pleno de los territorios a los pueblos indígenas y su vivencia según la cosmogonía propia. Segundo debe comenzarse a implantar modelos de la democracia deliberativa para desarrollar procedimientos y prácticas institucionales para alcanzar decisiones en materias que concierne a todos, donde converge diferentes valores plurales y conflictos de intereses sobre la vida social como son las esencias constitucionales, para tener soluciones entre la dicotomía liberal derechos individuales y libertades, y en el caso particular en el multiculturalismo. 


\section{Referencias}

1. Agrawal, A. 1995. "Indigenous and scientific knowledge: some critical comments". Indigenous Knowledge and Development Monitor., Recuperado en: http://www.nuffic. nllciran/ikdm/3-3/agrawal.html

2. Álvarez, L. (2004). La Jurisdicción Especial Indígena en Colombia Y Los Mecanismos De Coordinación Con El Sistema Judicial Nacional. Recuperado de: http://www.dplf. org/uploads/1184704476.pdf

3. Andolina, Robert. 2003. "The Sovereign and Its Shadow: Constituent Assembly and Indigenous Movement in Ecuador". Journal of Latin American Studies.35,4: 721-750. Recuperado en http://www.jstor.org/stable/3875830.

4. Ariza R. (2008) "Teoría y práctica en el ejercicio de la jurisdicción especial indígena en Colombia”. En: Huber R., et al. (Ed). Hacia sistemas jurídicos plurales. Reflexiones y experiencias de coordinación entre el derecho estatal y derecho indigena. Bogotá: Ediciones Antropos Ltda.

5. Ariza, R. (2010). Coordinación entre sistemas jurídicos y administración de justicia indígena en Colombia. San José: Instituto Interamericano de Derechos Humanos Coordinación entre sistemas jurídicos y administración de justicia indígena Colombia / Instituto Interamericano de Derechos Humanos.

6. Asociación de Cabildos Juan Tama. Programa Tierradentro Cxhab Wala (ACIN). (2005). Kwe'sx Çxhakwesame Fxizzenis Na Kiwete Kiumna Ustha'w Phuphna, Çxäçxha Yahtxna Yujuwaisa (Reconstruyendo el Derecho Propio Protegemos la Vida, para Seguir en Resistencia). Santander de Quilichao. 2002-2004.

7. BBCNEWS. (2010). "Indigenous rights outlined by UN". Recuperado en: http://news.bbc.co.uk/2/hi/in_depth/6993776.stm

8. Barona, G. \& Rojas, J. (2008). Falacias del pluralismo jurídico y cultural en Colombia. Popayán: Universidad del Cauca.

9. Bebbington, A. (1993). "Modernization from below: An Alternative Indigenous Development?". Economic Geography. 69, 3: 274-292. Recuperado en:. http://www.jstor.org/stable/143451

10. Benhabid S .(1996) Democracy and Difference. Princeton: P.U.P.

11. Boyle, A. (1999). "Some Reflections on the Relationship of Treaties and Soft Law". The International and Comparative Law Quarterly No. 4, 42:890-930.

12. Colchester, M. "Indigenous Rights and the Collective Conscious". Anthropology Today. 18, 1: 1-3. Recuperado en: http://www.jstor.org/stable/3695132

13. Comité de Derechos Económicos, Sociales y Culturales (2002). "Cuestiones sustantivas que se plantean en la apli- cación del Pacto Internacional de Derechos Económicos, Sociales y Culturales. Observación general № 15". Recuperado en: http://www.derechos.org.ve/pw/wp-content/uploads/ ObsGral_151.pdf

14. Coordinadora Andina de Organizaciones Indígenas CAOI. 2010. Buen Vivir/Vivir Bien. Filosofía, Politicas, Estrategias y Experiencias Regionales Andinas. Lima: CAOI.

15. Cruz E. (2008) "Principios generales del derecho indígena". En: Huber R., et al. (Ed). Hacia sistemas juridicos Plurales. Reflexiones y experiencias de coordinación entre el derecho estatal y derecho indigena. Bogotá: Ediciones Antropos Ltda.

16. Centro de Recursos para el Análisis de Conflictos - CERAC. (2011). Riesgo por presencia de grupos armados ilegales en Colombia. Recuperado en: http://moe.org.co/home/doc/ moe_mre/2011/mre2011/12_armadosilegales.pdf

17. Departamento Administrativo Nacional de Estadística DANE. (2007). Colombia una nación multicultural. Su diversidad étnica. Bogotá: DANE.

18. De Kerchove, M. (1997). El Sistema Juridico entre Orden y Desorden. Madrid: Universidad Complutense de Madrid.

19. Fitzpatrick, Peter (1998). La mitología del derecho moderno. México: Siglo XXI.

20. Fraser, Nancy. Reflexiones críticas desde la posición post socialista. En: Iustitia Interrupta.

21. García, M. (2013) Entrevista realizada en la investigación. Abogado de la ONIC.

22. García V., M.\& Santos, B. (2001). El Caleidoscopio de las Justicias en Colombia Tomo I. Bogotá: Panamericana Formas e Impresos.

23. Gaviria, C. (1998). Justicia Indígena en la Constitución Colombiana de 1991. En CEDLA, Taller Internacional El Reto de la Diversidad: Pueblos Indigenas y Reforma del Estado en América Latina. Conferencia llevada a cabo en CEDLA, Holanda, Amsterdam.

24. Gómez H. (2006) Justicias orales indígenas y sus tensiones con la ley escrita. En RELAJU, Justicia y diversidad en tiempos de globalización. Conferencia llevada a cabo en el V Congreso de la Red Latinoamericana de Antropología Jurídica, México, Oaxtepec, Morelos.

25. Gros, C. (2003). Politicas de la Etnicidad: Identidad, Estado y Modernidad., Bogotá: Instituto Colombiano de Antropología E Historia

26. Hespanha, A. (1993). "Sabios y Rústicos. La Dulce Violencia de la Razón Jurídica”, en La Gracia Del Derecho. Madrid: Centro de Estudios Constitucionales. Madrid.

27. Hettne. (1996). "Ethnicity and development: an elusive relationship". En Ethnicity and Development: Geographical 
Perspectives. Editado por D Dwyer \& D Drakakis-Smith. Chichester: John Wiley.

28. Iniciativa sobre Pobreza y Desarrollo Humano de la Universidad de Oxford (2013, 4 de junio) .Pobreza multidimensional: de la teoría a la práctica. Revista Humanun. Recuperado: http://www.revistahumanum.org/blog/pobreza-multidimensional-de-la-teoria-a-la-practica/

29. Jumi, G. (2010). "Plan de Desarrollo de los Pueblos Indígenas". Consultado el 15 de septiembre. http://www. gerardojumi.info/-noticias/106-en-plan-de-desarrollo-pueblos-indigenas-plantean-un-estado-plurinacional-

30. Kenrick J. \& Jerome L. (2004). "Indigenous Peoples' Rights and the Politics of the Term 'Indigenous'". Anthropology Today. 20, 2: 4-9. Recuperado en: http://www.jstor.org/ stable/3695107

31. Mackay, Fergus. 2008. ¿’or qué es importante la nueva sentencia interpretativa de la CIDH en el caso SaramakaSurinam?. Recuperado en: http://www.politicaspublicas.net/ panel/siddhh/cidh/111-nueva-sentencia-de-la-cidh-en-el-caso-saramaka-implicancias-para-los-pueblos-indigenas-html

32. Martínez, M.(1999). Study on treaties, agreements and other constructive arrangements between States and Indigenous populations. New York. United Nations.

33. Marks, S. (2004). "The Human Right to Development: Between Rhetoric and Reality". Harvard Human Rights Journal. 17: 137-168.

34. Merry, S. (1988). "Legal Pluralism". Law and society, 22,(5), pp.869-896.

35. Naciones Unidas (2009). Informe sobre el desarrollo bumano 2009. Superando barreras: movilidad y desarrollo bumanos. Nueva York: Programa de las Naciones Unidas para el Desarrollo, PNUD.

36. Muñoz, H. (2013). Entrevista realizada en la investigación. Abogado de la OPIAC.

37. Orellana, R. (2005) "Derecho indígena -campesino: producto y proceso de reinvenciones inter-legales. En Ardila, E. et al, La Justicia Comunitaria Como Ruta Para La Democracia. Bogotá: Red de Justicia Comunitaria.

38. Organización de las Naciones Unidas. (1976) "Pacto Internacional de Derechos Económicos, Sociales y Culturales". Recuperado en: http://www2.ohchr.org/spanish/law/cescr.htm

39. Perafán, C. (1995) Sistemas jurídicos Paez, Kogi, Wayún y Tule. Santafé de Bogotá: Instituto Colombiano de Antropología y Colcultura.

40. Perafán, C, Azcárate, L. \& Zea H. (2000). Sistemas jurídicos tukano, chamí, guambiano y sikuani. Bogotá: Ministerio de Cultura. Colciencias.

41. Programa Presidencial para la Formulación de Estrategias y Acciones para el Desarrollo Integral de los Pueblos
Indígenas de Colombia. (2013). Memoria Taller Nacional Planes Integrales de Vida. Recuperado en: www.pueblosindigenas.gov.co

42. Programa de Naciones Unidas para el Desarrollo (PNUD). (2005). La cooperación internacional ante una encrucijada. Ayuda al desarrollo, comercio y seguridad en un mundo desigual. New York: Ediciones Mundi-prensa.

43. Programa de Naciones Unidas para el Desarrollo (PNUD). (2013) La otra visión: Pueblos Indigenas y los ODM. Bogotá: PNUD.

44. Rajagopal, B. (2005). El derecho internacional desde abajo. El desarrollo, los movimientos sociales y la resistencia del tercer mundo. Bogotá: Ilsa.

45. Rico, L. (2009). "La consulta previa: la farsa Multicultural". La Silla Vacia. Recuperado en: http://www.lasillavacia. com/historia/3201

46. Rodríguez, G. (2005). "La Consulta Previa a Pueblos Indígenas". Comunidades Étnicas en Colombia. Cultura y Jurisprudencia. Bogotá: Universidad del Rosario.

47. Sánchez, E. (2008). "Principios básicos y formas de funcionamiento de la justicia que se imparte entre los paeces y los wayú como forma cultural adecuada, legítima y viable para resolver conflictos y coaccionar a sus sociedades particulares". En: Huber R., et al. (Ed). Hacia sistemas jurídicos plurales. Reflexiones y experiencias de coordinación entre el derecho estatal y derecho indigena. Bogotá: Ediciones Ántropos.

48. Sand P. (2003). Principles of International Environmental Law. Cambridge: Cambridge University Press

49. Sánchez, E., Roldan, R \& Sánchez, M. (1993). Derechos e identidad: los pueblos indígenas y negros en la Constitución Politica de Colombia de 1991. Santafé de Bogotá: COAMA.

50. Sánchez, E. (1998). Justicia y pueblos indigenas de Colombia: la tutela como medio para la construcción de entendimiento intercultural. Bogotá: Universidad Nacional de Colombia.

51. Sánchez, E. (2004). Justicia y Pueblos Indígenas de Colombia. Bogotá: Universidad Nacional de Colombia-Unidad de Investigación Jurídico-Sociales y Políticas "Gerardo Molina" (UNIJUS).

52. Sánchez, B. \& Jaramillo, I. (2007). La Jurisdicción especial indigena en Colombia. Bogotá: Instituto de Estudios del Ministerio Público. Procuraduría General de la Nación.

53. Santos, B. (2001). Estado, Derecho y Luchas Sociales. Bogotá: ILSA - Instituto Latinoamericano de Servicios Legales Alternativos.

54. Santos, B. (2001). "El Derecho y la Comunidad: Transformaciones recientes de la naturaleza del poder del estado en los países capitalistas avanzados". Estado, Derecho Y Luchas Sociales. Bogotá: ILSA-Instituto Latinoamericano de Servicios Legales Alternativos. 
55. Sierra, M. (2005) "Diversidad cultural, género y derechos: retos para la justicia indígena”. En Ardila, E. et al, La Justicia Comunitaria Como Ruta Para La Democracia. Bogotá: Red de Justicia Comunitaria.

56. Souza, M. (2001). El Uso Alternativo del Derecho. Bogotá: Unibilblos.

57. Stavenhagen, R. (1990) "Derecho consuetudinario indígena en América Latina”. Entre la Ley y la Costumbre, Instituto Indigenista Interamericano e Instituto Interamericano de Derechos Humanos, México. pp.27-28

58. Teteye, B. (2013) Entrevista realizada en la presente Investigación. Miembro de la Junta de la OPIAC.

59. Turner, T. (2003). "Class projects, social consciousness, and the contradictions of "globalization" En Violence, the state and globalization, editado por Jonathan Friedman, 20100 New York: Altamira.

60. United Nations. 2009. State of the World's Indigenous Peoples. New York: United Nations.

61. United Nations. (2010). "United Nations adopts Declaration on Rights of Indigenous Peoples”. Recuperado de: http:// www.un.org/apps/news/story.asp?NewsID $=23794 \& C r=$ indigenous\&Cr1 =
62. Universidad Nacional de Colombia Sede Orinoquia (2010) Proceso de formación: Gobierno y Justicia Propios. Guia de Trabajo. Bogotá: UNHCR-ACNUR.

63. Van C. \& Donna L. (2003). "Andean Indigenous Movements and Constitutional Transformation: Venezuela in Comparative Perspective". Latin American Perspective. 3 I. 49-69. Recuperado en: http://www.jstor.org/stable/3184965

64. Wellmer Albrecht. (1996) "Condiciones de una cultura democrática” en Finales de Partida, Madrid., pp. 77-101.

65. Wolkmer, C. (2006). Pluralismo Jurídico. Sevilla: MAD

66. World Commission on Development and Environment. (1987). Our common future. Oxford: Oxford University Press.

67. Yrigoyen, R. (2004). "Pluralismo jurídico, derecho indígena y jurisdicción especial en los países andinos". El otro derecho. 30. Bogotá: ILSA.

68. Young, M. (1998). "A New Handbook of Political Science". Contributors: Robert E. Goodin - editor, Hans-Dieter Klingemann - Oxford: Oxford University Press. 